Çukurova Üniversitesi Mühendislik Mimarlık Fakültesi Dergisi, 30(2), ss., 243-253, Aralık 2015

Çukurova University Journal of the Faculty of Engineering and Architecture, 30(2), pp. 243-253, December 2015

\title{
Elazı̆g Bölgesi Travertenlerinin Kaplama Taşı Olarak Kullanılabilirliğinin Belirlenmesi
}

\author{
Esma KAHRAMAN"1, Ayten ESER ${ }^{1}$ \\ ${ }^{1}$ Çukurova Üniversitesi, Mühendislik Mimarlık Fakültesi, Maden Mühendisliği Bölümü, Adana
}

Geliş tarihi: 09.11.2015 Kabul tarihi:30.12.2015

\section{Özet}

Traverten, pek çok avantajı nedeniyle yaygın olarak kullanılan bir kaplama taşıdır. Bu çalışma kapsamında, Elazığ Keban Bölgesinde üretim faaliyetinde bulunan bir sahanın farklı bölgelerinden alınan travertenlerin kaplama taşı olarak kullanılabilirliği TS EN ve BS EN standartlarına göre değerlendirilmiştir. Yapılan çalışmada, görünüş, eğilme dayanımı, su emme katsayısı, yangın karşısındaki davranışı, kılcal etkiyle su emme, açık gözeneklilik, görünür yoğunluk ve don sonrası eğilme dayanımı değerleri bulunmuştur. Çalışma sonucunda; Elazığ travertenlerinin don oluşumu olmayan, az yağış alan bölgelerde kaplama taşı olarak kullanılabileceği sonucu ortaya çıkmıştır.

Anahtar Kelimeler: Doğal taş, Elazı̆̆ traverten, Kaplama taşı

\section{Determination of the Possible Usability of Elazı̆ Travertine as Cladding Slab}

\begin{abstract}
Travertine, is a coating vehicle widely used because of many advantages In this study the usability of

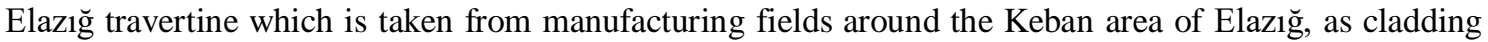
slab is evaluated according to the TS EN and BS EN standards. In this study, appearance, flexural strength, water absorption coefficient, action against fire, capillary action of water absorption, open porosity, apparent density and bending strength value after frost were found. In conclusion; the results has emerged that Elazığ travertine can be used as coating in stone in low rainfall areas without frost formation
\end{abstract}

Keywords: Marble, Elazığ travertine, Cladding slab

\footnotetext{
* Yazışmaların yapılacağı yazar: Esma KAHRAMAN, Çukurova Üniversitesi, Mühendislik Mimarlık Fakültesi, Maden Müh. Bölümü, Adana, ekahraman@cu.edu.tr
} 


\section{GíRİs}

Elazı̆̆ ilimizde pek çok doğal taş üretimi yapılmaktadır. Bunlar başta vişne mermeri olmak üzere petrol yeşili mermeri, oniks, traverten, bej mermer ve sunta mermeri olarak siralanmaktadır. $\mathrm{Bu}$ doğal taş çeşitliliği Elazı̆̆ ilimizi dünya ve ülkemiz pazarlarında önemli bir konuma getirmiş̧tir.

Travertenin doğal kaplama malzemesi olarak kullanımı oldukça yaygındır. Bunun nedenleri [1];

- Homojen olarak dağılmış boşluk yapısından dolayı 1S1 ve sese karşı yalıtım sağlayan en önemli doğal taşlardandır.

- Yapısındaki boşluklar yapının nefes almasını sağlayarak nem ve kokuyu absorbe edebilmektedir.

- Kaplama olarak kullanilan yerlerde mevcut olan iç aydınlatmayı yansıtmazlar.

- Boşluk oranından dolayı özgül ağırlığı düşük olduğu için hafif bir malzemedir.

- Islak zeminlerde yüzeydeki boşluklar sebebiyle kayganlaşmaya neden olmazlar.

Bu çalışmada Elazı̆̆ Keban bölgesinde üretilmekte olan travertenin kaplama taşı olarak kullanımı incelenmiştir. Şekil 1'de travertenin makroskobik görüntüsü verilmiştir.

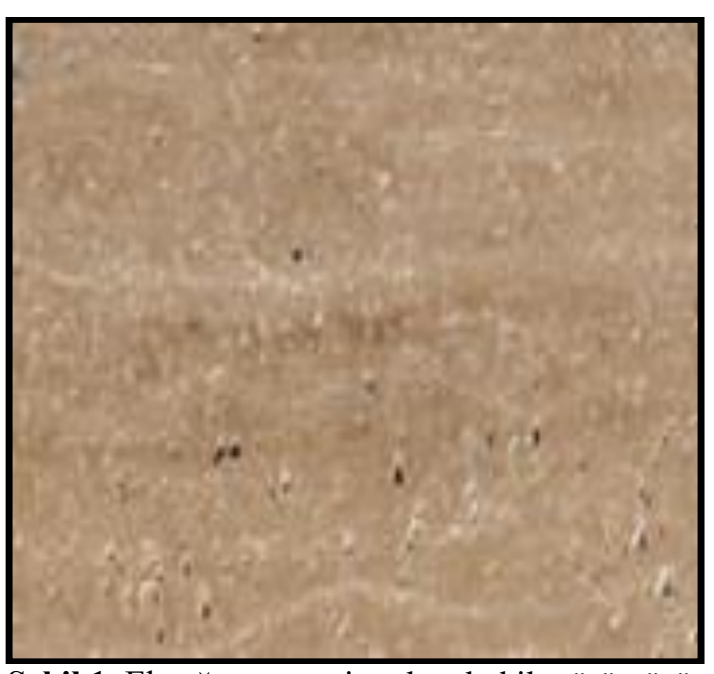

Şekil 1. Elazığ traverteni makroskobik görüntüsü
Travertenin en yaygın olduğu kullanım alanları; konutların ve diğer yapıların iç ve dış mekanları, havuz çevreleri, dış cephe kaplamaları, yürüyüş yolları ve park-bahçe düzenlemeleri olarak sıralanabilir. Mermer ve doğal taşlarda Avrupa'ya uygunluk (CE) belgesi alabilmek için bazı standartlara uyması gerekmektedir.

$\mathrm{Bu}$ amaçla bu çalışma kapsamında, Elazığ travertenlerinin "görünüş, eğilme dayanımı, darbe dayanımı, tek eksenli basınç dayanımı, atmosfer basıncı altında su emme, yangın karşısındaki davranışı, kılcal etkiyle su emme, görünür yoğunluk ve açık gözeneklilik, dona dayanım" değerleri belirlenmiştir.

\section{2. ÇALIŞMA ALANI}

\subsection{Coğrafi Konum}

Elazı̆̆ İli, Keban İlçesi sınırlarında bulunan traverten ocağ 1 özel bir firma tarafindan işletilmektedir.

Çalışma sahası Elazı ̆ İline 60 km, Keban İlçesine $10 \mathrm{~km}$ uzaklıkta bulunmaktadır. Ulaşım D 260 karayolu üzerinden sağlanmaktadır. Bölgede çeşitli büyüklüklerde pek çok mermer ve doğal taş üreten işletme bulunmaktadır. Çalışma alanının yer bulduru haritası Şekil 2'de, sahalara ait uydu fotoğrafi ise Şekil 3'de verilmektedir.

\subsection{Bölgesel Jeoloji}

İnceleme alanında Üst Kretase yaşlı Elazı̆̆ Magmatitlerine ait kayaçlar yüzeylemektedir. Bölgede Elazığ magmatitleri, tonalitik bileşimli derinlik kayaçları, bazaltik ve dasitik bileşimli volkanitler ve volkano-sedimanter birimlerle temsil edilmektedir.

Tonalitik derinlik kayaçları ve dasitik volkanitler temeldeki en yaşlı birim olan bazaltik kayaçları kesmektedir. Bazaltik kayaçların üzerine yer yer dasitik ve andezitik volkanitleri içeren bir volkano-sedimanter istif gelmektedir. Ayrıca aplit, lamprofir, mikrotonalit ve tonalit porfir bileşimli yarı derinlik kayaçları da inceleme alanında gözlenmektedir [2]. 


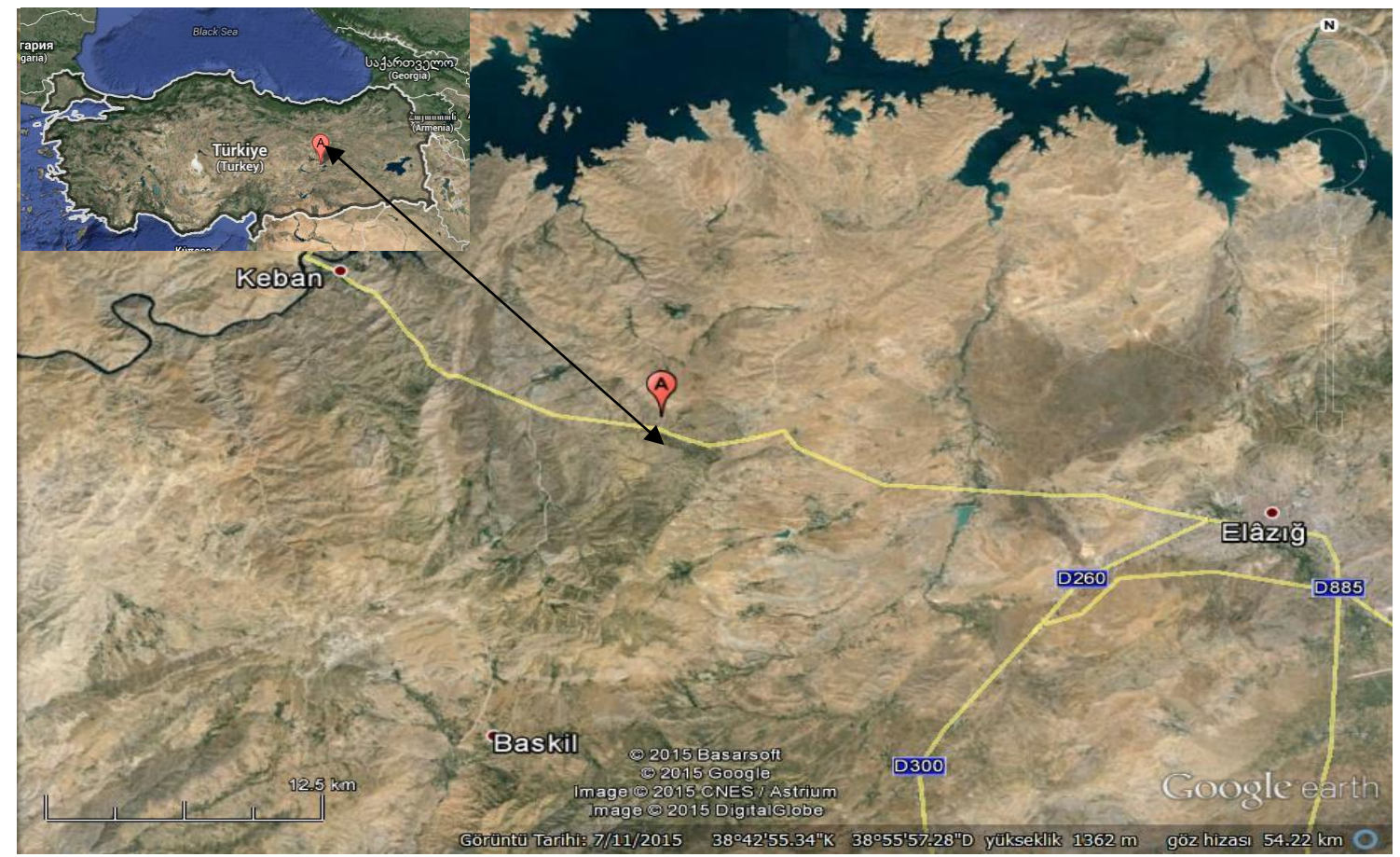

Şekil 2. Çalışma alanının yer bulduru haritası

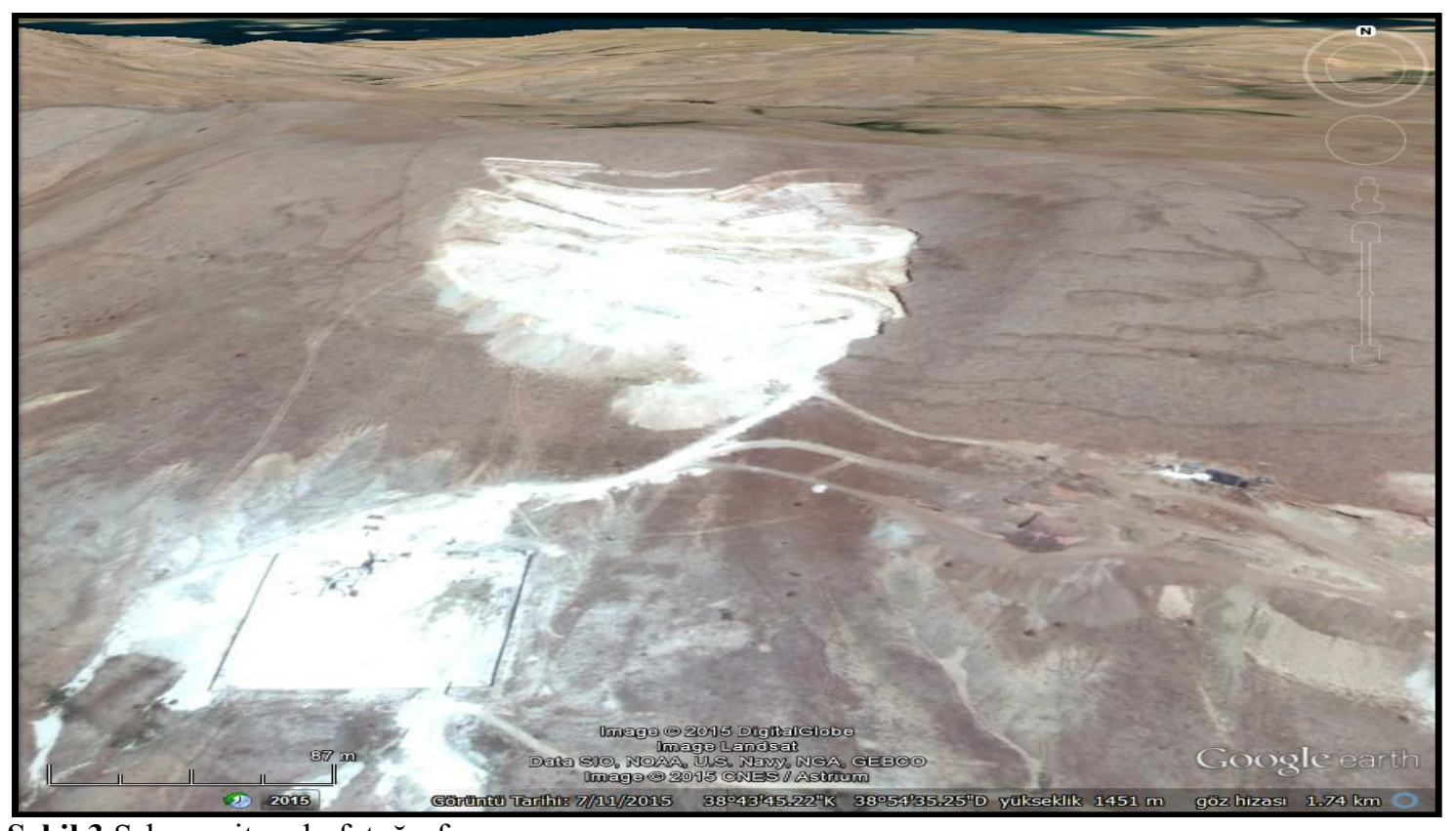

Şekil 3.Sahaya ait uydu fotoğrafi 


\section{METOD}

Bu çalışma kapsamında, bahsi geçen bölgede üretim yapan sahadan alınan travertenlerin kaplama taşı olarak kullanılabilirliğinin TS EN 1469 [3] standardı ile ele alınarak, TS 699 [4], TS EN 1936 [5], TS EN 1925 [6], BS EN 13755 [7], BS EN 12372 [8], TS EN 12407 [9] ve TS EN 12371 [10] standartlarına göre deneylere tabi tutularak belirlenmesidir. Deney numuneleri TS EN 1469 [2]'da belirtilen kaplama taşı olarak kullanılabilme esası göz önüne alınarak başlıca özellikleri standartlarda belirtilen yöntemlerle analize tabi tutulmuştur.

\subsection{Görünüş}

Doğal yapı taşlarının rengi, damarları, dokusu ve bunun gibi özellikleri görünüş özelliğinin belirlenmesini sağlamak için aynı taş tipini referans numunesi üzerinde gözle incelenerek tanımlanmalıdır. Referans numuneler nihai işlemle elde edilen görünüşü ortaya koyacak yeterli büyüklükteki doğal taştan mamul uygun sayıdaki parçalar olmalıdır. Parçaların yüzey alanı en az $0,01 \mathrm{~m}^{2}$ olmalı ve renklenme, damar izi, fiziksel yap1 ve yüzey perdahlaması ile ilgili görünüş değişimleri taşı temsil edecek şekilde olmalıdır. Referans numune, numune ve kullanım yeri arasında birebir olarak benzer olduğu anlamına gelmez; doğal farklılıklar daima bulunabilir [3].

\subsection{Petrografik ve Mineralojik Analiz}

Doğal taş ve mermer örneklerinin petrografik ve mineralojik incelenmesinin yapılması için örnekten ince kesitler hazırlanmalı ve bu kesitler polarizan mikroskobuyla incelemelidir [9]. Kayaçta mevcut şeffaf minerallerin incelenmesi için petrografi mikroskobu kullanılmaktadır. Kayaçtan hazırlanmış ince kesit petrografi mikroskobunda içinden geçen 1şının kazandığı özelliklerin saptanmasiyla tanımlanmaktadır. Burada kayacı oluşturan minerallerin cinsleri, kristal boyutları, mineraller arasındaki dokusal ilişkiler, gözeneklilik, damar dolgu tipi ile mineral, çatlak ve damar yönlenmeleri, bozunma ürünleri ve dağılımları saptanmaktadır.

\subsection{Tek Eksenli Basınç Dayanımı}

Basınç dayanımı, belirli bir yüke karşı kayaçların kırılmadan önceki maksimum dayanabilme yeteneği olarak tanımla bilmektedir. Deney numunesi düzgün geometrik şekilli küp, prizma veya karot şeklinde olabilmektedir. Karot numunelerinde boy/çap oranının 2-2,5 arası olması istenmektedir. Hidrolik pres numune üzerine düşey olarak yük uygulayabilecek ve uygulanan yükü ölçerek gösterebilecek bir sistemden oluşmaktadır. Deney numunesinin alanını belirlemek için yük uygulanacak alanın ölçümleri kumpas yardımıyla yapılmalıdır. Hidrolik basınç ünitesinin ortasına yerleştirilen numuneye yük uygulanmaya başlanır ve kırılma yükü kaydedilerek aşağıdaki Eşitlik (1) yardımı ile tek eksenli basınç dayanımı değeri bulunur.

$$
\sigma_{b}=\frac{P}{A}
$$

$\sigma_{\mathrm{b}}:$ Taşın basınç mukavemeti $\left(\mathrm{kgf} / \mathrm{cm}^{2}\right)$

P : Kırılmaya sebep olan en büyük yük (kgf),

A : Taşın yük uygulanan yüzünün alanı $\left(\mathrm{cm}^{2}\right)$.

\subsection{Darbe Dayanımı}

Darbe dayanımı; standart boyutlardaki kayaçların belirli bir doğrultuda, darbelere karşı gösterdiği dirençtir. Kayacın darbe dayanımlarının belirlenmesi için numune boyutlarının 40x40x40 $\mathrm{mm}$ boyutlarında hazırlanmalıdır [4]. Darbe dayanım deney düzeneği kullanılarak yapılmaktadır. Darbe dayanımı deney düzeneğine numune yerleştirilir ve bunun üzerine çelik plaka yerleştirilir ve deney tokmağının düşürüleceği yükseklik aşağıda verilen Eşitlik 2 ve 3 ile hesaplanır ve hesaplanan yükseklikten düşürülür.
$\mathrm{H}=0,04 . \mathrm{V}$
$\mathrm{Dn}=\mathrm{n}(\mathrm{n}+1)$
H : Tokmağın düşme yüksekliği $(\mathrm{cm})$,
$\mathrm{V}$ : Deney numunesinin hacmi $\left(\mathrm{cm}^{3}\right)$,
Dn: Numunenin darbe dayanımı $\left(\mathrm{Nmm} / \mathrm{mm}^{3}\right)$,
$\mathrm{N}$ : Kirılmaya sebep olan darbe sayısı. 


\subsection{Eğilme Dayanımı}

Eğilme Dayanımı, BS EN 12372 [8] standardına uygun olarak deney numuneleri $50 \times 50 \times 300 \mathrm{~mm}$ boyutlarına getirilir ve onar adet örnek hazırlanır. Hazırlanan numuneler 0,01 gr hassasiyetli elektronik terazide tartılarak $70 \pm 5^{\circ} \mathrm{C}^{\prime}$ de etüvde sabit tartıma gelinceye kadar bekletilir. Desikatörde 1sısı yaklaşık $20^{\circ} \mathrm{C}$ oluncaya kadar bekletilir. Desikatörde 24 saatten fazla muhafaza edilmemelidir. Kuru ve temiz yüzeyler mesnet noktalarına uygun ölçekte yerleştirilir bu yerleştirmede mesnet aralıklarının merkezinin yükün uygulandığı merkezle çakışmalıdır. Yani yükleme mesnet aralı̆g $200 \pm 1 \mathrm{~mm}$ olmalıdır. Yükleme sabit bir şekilde artmalı ve yükleme hızı $0,25 \pm 0,05 \mathrm{MPa} / \mathrm{s}$ olarak belirlenmeli ve eğilme test cihazında örnek kırılana kadar yükleme devam etmelidir. 10 örnek için aynı işlem tekrarlanmalı ve kırılma yükleri kaydedilmelidir [8].

\subsection{Atmosfer Basınci Altında Su Emme}

TS EN 1469 [3] standardında atıf yapılan BS EN 13755 [7]'e göre 6 adet 50 mm'lik küpler hazırlanır. Hazırlanan numuneler tartilır ve sabit tartıma kader etüvde $70 \pm 5{ }^{\circ} \mathrm{C}$ 'de kurutulur ve 0,01 gr hassasiyetli elektronik terazide tartılır. Sabit tartıma gelen numuneler desikatörde soğutulur. Örnekler deney tankının içerisine tankın tabanından $15 \mathrm{~mm}$ olacak şekilde su emmeyen çubukların üzerine 6 adet örnek dizilir. Şekilde su sıcaklı̆ğ $20 \pm 10{ }^{\circ} \mathrm{C}$ olmak üzere tankın üzerine yavaş bir şekilde su eklenir. Su seviyesi örneklerin yarısına kadar gelmelidir. Su eklendikten sonra $60 \pm 5$ dakika sonra su seviyesi numunenin boyunun $3 / 4$ 'ne ulaşıncaya kadar yükseltilir. Başlangıç süresinden itibaren $120 \pm 5$ dakika sonra bütün numuneler komple suyun altında kalmak koşuluyla ( $\mathrm{Su}$ seviyesi örneklerin tepe noktasından en az $25 \pm 5 \mathrm{~mm}$ yüksekte olmalıdır) su eklenmelidir. $\mathrm{Bu}$ vaziyette başlangıç süresinden itibaren $48 \pm 2$ saat beklemelidir. Süre sonunda suyun içinden alınarak hizlıca nemli bir bezle kurulanan numuneler en geç bir dakika içerisinde $0,01 \mathrm{gr}$ hassasiyetli terazide tartılır. Her bir numune tartıldıktan sonra suyun içerisine tekrar bırakılır her $24 \pm 2$ saatte numuneler aynı şekilde tartılır ve sabit tartıma gelinceye kadar işleme devam edilir.
Bekleme süresince su seviyesinde eksilme olduğu durumlarda su eklenmelidir. Elde edilen tartım verileri kullanarak aşağıdaki formülle her bir numune için atmosfer basıncı altındaki su emme oranı eşitlik 4 ile hesaplanır.

$A b=\frac{\mathrm{m}_{\mathrm{s}-} \mathrm{m}_{\mathrm{d}}}{\mathrm{m}_{\mathrm{d}}} \times 100$

$\mathrm{m}_{\mathrm{d}}:$ Kuru numune ağırlı̆̆ 1

$\mathrm{m}_{\mathrm{s}}$ : Doygun ağırlık

$\mathrm{Ab}$ : Atmosferik basınç altında su emme

\subsection{Yangın Karşısındaki Davranışı}

TS EN 1469 [3]'a göre doğal taşın kütlece veya hacimce (herhangi birisinin) \%1'den fazla asfaltit ihtiva etmesi ve nihai kullanım yerinde yangınla ilgili düzenlemeler tabi olması durumunda yangına karşı davranışı TS EN 13501-1+A1 [11]'e göre incelenmektedir [11].

Doğal taşın işlenmesi sırasında doğal delikler, kırıklar, çatlaklar vb. için kullanılan organik yapıştırıcı dolgu malzemeleri veya benzeri ürünlerin kütlece veya hacimce herhangi birisinin $\% 1$ 'den fazla olması ve yangınla ilgili düzenlemeler tabi olması durumunda yangına karşı davranışı TS EN 13501-1+A1 [11]'e göre deneye tabi tutulmalı ve sinıflandırılmalıdır [2].

\subsection{Kılcal Etkiyle Su Emme}

Deney numuneleri; küp olarak $70 \pm 5 \mathrm{~mm}$ veya $50 \pm 5 \mathrm{~mm}$, silindir olarak $70 \pm 5 \mathrm{~mm}$ veya $50 \pm 5 \mathrm{~mm}$ çapında ve çapı boyuna eşit olan 6 adet numune hazırlanır. Deney numuneleri $(70 \pm 5){ }^{\circ} \mathrm{C}$ 'de havalandırmalı etüvde sabit kütleye gelinceye kadar kurutulmalı ve, $(20 \pm 5){ }^{\circ} \mathrm{C}$ oda sicaklığına erişinceye kadar bir desikatörde tutulur. Kurutma sonrası numune $0,01 \mathrm{~g}$ yaklaşımla tartılır (md) ve $0,1 \mathrm{~mm}$ yaklaşımla küp şekilli numunelerde kenar ortaylar, silindirik numunelerde ise birbirine dik iki çap ölçülerek su emdirilecek yüzey hesaplanır. $\mathrm{Bu}$ alan $\mathrm{m}^{2}$ cinsinden ifade edilir. Deney numuneleri yalnızca altlarında kısmen mesnet vazifesi görecek olan, tanktaki dayanakların üzerine yerleştirilir. Suyun yükselişine bağlı olarak 
istenilen anizotropi düzlemlerinin pozisyonu şartlara uygun olarak ayarlanır. Numunenin tabanı $(3 \pm 1) \mathrm{mm}$ derinliğe daldırılır ve zaman ölçer (kronometre) çalıştırılır. Deney boyunca gerektiği kadar tanktaki su seviyesinin sabit tutulması sağlanır ve numunelerin nemini kaybetmemesi amacıyla tankın kapağı kapatılır. Zaman aralıklarında, başlangıçta çok kısa, sonra uzun olacak şekilde her bir numune sudan çıkarılır, kuru bölümden hafifçe tutularak nemli bir bez kullanılarak bütün su damlacıkları yüzey üzerinden uzaklaştırılır ve hemen 0,01 g yaklaşımla tartılır. Sonra yeniden tanka yerleştirilir. Deneyin başlangıcından itibaren her bir tartım arasında geçen zaman kaydedilir. Zamanların seçimi kayacın tipine göre değişmektedir. Oldukça yüksek emişli bir kayaç için uygun süreler: $t_{1},(1,3,5,10$, $15,30,60,480$ ve 1440$)$ dakikadır. Düşük emişli bir kayaç için uygun süreler: 30, 60, 180, 480, 1440, 2880 ve 4320 dakika. Bu süreler \%5 yaklaşımla ölçülür. Minimum 7 ölçüm gereklidir. Ardışık iki tartım arasındaki fark, numunenin emdiği su kütlesinin \%1' inden az ise deneyin sona erdiği kabul edilir. Emilen suyun gram cinsinden kütlesi, numunenin $\mathrm{m}^{2}$ cinsinden taban alanına bölünerek, saniye cinsinden sürenin kareköküne karşı çizilmiş bir grafik olarak gösterilir. Eğri üzerinde değişimin bittiği noktadaki değerler ile eşitlik 5 kullanılarak kılcal etkiyle su emme oranı belirlenir [6].

$C: \frac{m_{i-} m_{d}}{A \sqrt{t_{i}}}\left(\mathrm{~g} / \mathrm{m}^{2} \times \mathrm{s}^{0,5}\right)$

$\mathrm{m}_{\mathrm{i}}$ : Doygun ağırlık

$\mathrm{m}_{\mathrm{d}}:$ Kuru ağırlık

A : Su emdirilen yüzey alanı

$\mathrm{t}_{\mathrm{i}} \quad$ : Doygun ağırlığa ulaşılan sürenin karekökü

\subsection{Açık Gözeneklilik ve Görünür Yoğunluk}

Deney numuneleri silindirik küp veya prizma şeklinde olabilir. Bu numuneler, elmaslı testere veya karot alma makinesi ile hazırlanmalıdır. Geometrik ölçümlerle hesaplanan görünür hacimleri en az $25 \mathrm{ml}$ olmalıdir. Numuneler $70 \pm 5{ }^{\circ} \mathrm{C}$ sicaklikta sabit kütleye gelinceye kadar kurutulmalıdır. Biri birini izleyen 24 saat aralıklı iki tartım arasındaki fark numune kütlesinin $\% 0,1$ 'den büyük değilse numunenin sabit kütleye ulaştığı kabul edilir. Daha sonra numuneler oda sıcaklığına erişinceye kadar desikatörde bekletilir. $\mathrm{Bu}$ şekilde her bir numune tartılır bir vakum kabına yerleştirilir ve basınç kademeli olarak yaklaşık 2 kPa'a kadar indirilir. Numunelerin açık gözeneklerindeki havayı uzaklaştırmak için yaklaşık iki saat bu basınç altında muhafaza edilir. Süre sonunda yaklaşı $20 \quad{ }^{\circ} \mathrm{C}$ sıcaklıkta deminaralize su, yükselme hızı 15 dakikadan az olmayan bir süre içerisinde numunelerin tamamıyla su içerisinde kalacağı hızda yavaşça kaba eklenir. Suyun ilavesi sırasında basınç sabit tutulmalıdır. Bu aşamadan sonra kap içerindeki basınç atmosfer basıncına denk getirilmelidir. Numuneler 24 saat süre ile atmosfer basıncı altında bekletilmelidir. 24 saat tamamlandiktan sonra her bir numunenin sudaki kütlesi Arşimet terazisi ile tartılır ve tartımlar kaydedilir. Ardından nemli bir bezle kurulanarak hızlı bir şekilde suya doygun numunenin kütlesi belirlenir, eşitlik 6 ve eşitlik 7 kullanılarak hesaplanır [5].

$$
\begin{aligned}
& P_{o}: \frac{m_{s}-m_{d}}{m_{s}-m_{h}} \times 100 \\
& P_{b}: \frac{m_{d}}{m_{s}-m_{h}} \times p r h \\
& \mathrm{P}_{\mathrm{o}}: \text { Açık gözeneklilik }(\%) \\
& \mathrm{P}_{\mathrm{b}}: \text { Görünür yoğunluk }\left(\mathrm{kg} / \mathrm{m}^{3}\right) \\
& \mathrm{m}_{\mathrm{s}}: \text { Suya doygun kütle } \\
& \mathrm{m}_{\mathrm{h}}: \text { Su içerisindeki kütle } \\
& \mathrm{m}_{\mathrm{d}}: \text { Kuru ağırlık } \\
& \text { prh: } 20^{\circ} \mathrm{C} \text { 'deki suyun yoğunluğu }\left(998 \mathrm{~kg} / \mathrm{m}^{3}\right)
\end{aligned}
$$

\subsection{Dona Dayanım Deneyi}

50x50x300 mm boyutlarinda 20 adet deney numunesi hazırlanır 10 adet numuneye yukarıda bahsedilen aşamalara ve BS EN 12372 [8] standardına uygun olarak eğilme dayanımı deneyi uygulanır ve sonuçlar kaydedilir. Hazırlanan diğer 10 adet numune $(70 \pm 5){ }^{\circ} \mathrm{C}$ sicaklıkta sabit kütleye erişinceye kadar kurutulur. (24 \pm 2$)$ saat arayla yapılan iki tartım arasındaki fark, ilk tartımın $\% 0,1$ 'inden daha büyük değilse, numunenin sabit kütleye eriştiği kabul edilir. Numuneler birbirlerinden en az $15 \mathrm{~mm}$ uzaklıkta olacak şekilde, kapta dik olarak yerleştirilir. Sonra numune yüksekliğinin yarısına kadar $(20 \pm 10){ }^{\circ} \mathrm{C}$ 'deki su ilave edilir (t0). $\mathrm{t} 0+(60 \pm 5)$ 
dakika sonunda numunelerin yüksekliğinin 3/4' ü su

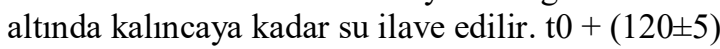
dakika sonunda numuneler bütünüyle suyun $(25 \pm 5) \mathrm{mm}$ altında kalacak şekilde su ilave edilir. Numuneler daha sonra (48 \pm 2$)$ saat süreyle su içerisinde bırakılır. Numuneler, uzun eksenleri düşey veya yatay olarak ve birbirlerine ve tankın cidarlarına değmeyecek şekilde tanka yerleştirilir ve birbirlerinden en az $10 \mathrm{~mm}$ ve tank cidarından da en az $20 \mathrm{~mm}$ uzaklıkta olacak şekilde konumlandırılırlar. Sıcaklık ölçme cihazını ihtiva eden referans numune, deneye tâbi tutulacak numunelerin ortasına yerleştirilir. Her 14 döngü sonunda (uygunsa daha az) numuneler, yatay ekseni etrafında 180 derece döndürülür. Her bir döngü, havada 6 saatlik donma periyodu ve bunu takip eden numunelerin suya daldırılmış durumda bulunduğu 6 saat' lik çözülme periyodundan ibarettir.

Döngüler, numuneler bozuluncaya veya verilmiş en büyük döngü sayısına erişinceye kadar tekrar edilmelidir. Döngüler esnasında izlenen referans numunenin merkezindeki sıcaklık değişimi, deneye tabi tutulan taşın görünür yoğunluğu, gözenekliliği ve su emmesiyle ilgili farklı soğutma, donma ve çözülme hızlarının sonucudur [10]. Her bir döngüde yapılması gereken işlemler Çizelge 1'de verilmiştir.

Çizelge 1. Donma çözünmede her bir döngüde yapılması gereken aşamalar [10]

\begin{tabular}{|c|c|c|}
\hline & $\begin{array}{c}\text { İzlenen numunenin } \\
\text { merkezindeki sicaklık }\end{array}$ & Süre \\
\hline $\begin{array}{c}\text { Döngünün } \\
\text { başlangıc1 }\end{array}$ & $\geq+5{ }^{\circ} \mathrm{C} \leq+20^{\circ} \mathrm{C}$ & $\mathrm{T} 0$ \\
\hline 1. kademe & $\leq 0{ }^{\circ} \mathrm{C} \geq-8^{\circ} \mathrm{C}$ & $\begin{array}{c}\mathrm{T} 0+2,0 \\
\text { saat }\end{array}$ \\
\hline 2. kademe & $\leq-8{ }^{\circ} \mathrm{C} \geq-12^{\circ} \mathrm{C}$ & $\begin{array}{c}\mathrm{T} 0+6,0 \\
\text { saat }\end{array}$ \\
\hline 3. kademe & $\mathrm{Tam}$ daldırma & $\begin{array}{c}\mathrm{T} 0+6,5 \\
\text { saat }\end{array}$ \\
\hline 4. kademe & $\geq+5^{\circ} \mathrm{C} \leq+20^{\circ} \mathrm{C}$ & $\begin{array}{c}\mathrm{T} 0+9,0 \\
\text { saat }\end{array}$ \\
\hline 5. kademe & $\geq+5^{\circ} \mathrm{C} \leq+20^{\circ} \mathrm{C}$ & $\begin{array}{c}\mathrm{T} 0+12,0 \\
\text { saat }\end{array}$ \\
\hline
\end{tabular}

Gerekli döngüler tamamlandıktan sonra numuneler suyun içerisinden çıkarılarak numunelerin oda sıcaklığına gelmesi beklenir ve daha sonra etüvde $(70 \pm 5)^{\circ} \mathrm{C}$ sicaklıkta sabit kütleye erişinceye kadar kurutulur. Kurutma işlemi sonrası tüm numunelere eğilme dayanımı deneyi standartlara uygun olarak gerçekleştirilir ve deneyin ilk aşamasında, 10 adet numuneden elde edilen eğilme dayanımı değerleri ile karşılaştırılarak aradaki farkın yüzdesel olarak değeri hesaplanır [10].

\section{ARAŞTIRMA BULGULARI}

Elazı̆̆ bölgesi travertenlerine bir önceki başlıkta bahsedilen ve standartlara uygun deneyler uygulanmış ve deney sonuçları aşağıda verilmiştir.

\subsection{Görünüş Deneyi Bulguları}

TS EN 1469 [3] standardına uygun olarak iki numune grubu incelenmiştir.

Referans numunenin rengi, damarları, dokusu yüzeyi perdahlanmış numune örneği ile benzerlik göstermektedir. Perdahlanmış yüzeylerde gözeneklerin şekli, dokusu ve rengi açıkça görülmektedir. Fakat perdahlanmış numune yüzeyindeki boşlukların perdahlama esnasında küçüldüğü gözlenmiştir.

Şekil 4 'de doğal ve perdahlanmış numuneler görülmektedir.

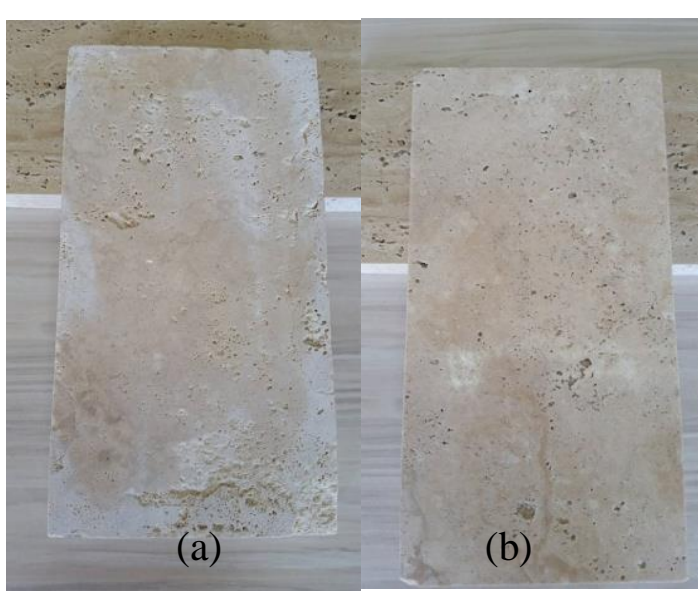

Şekil 4. Doğal (a) ve perdahlanmış (b) numuneler 


\subsection{Petrografik ve Mineralojik İnceleme Bulguları}

Kayaç; yüksek poroziteye sahip ve mikro kristalin dokulu olup sedimanter orijinlidir. Kayaç içerisinde farklı orijinli kayacın yaklaşık \%60-70'ini kapsayan spari dokulu fosil katkılarının mevcut olduğu gözlenmiştir. Gözlenen fosil kavkıları ve gözenekler Şekil 5'de görülmektedir.

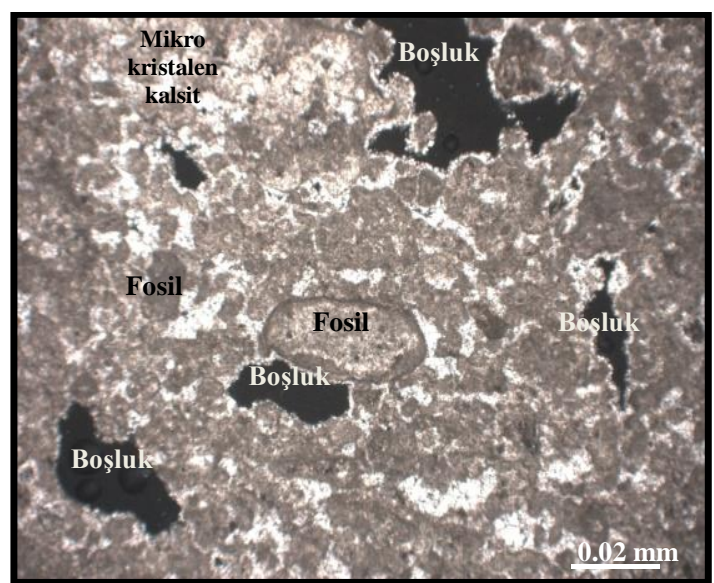

Şekil 5. Gözlenen fosil kavkı ve gözeneklilik

Fosiller yer yer kalsitleşmiștir (Şekil 6), kalsitleșen fosillerin bir kısmı öz şeklini korumaktadır. Fakat çoğu şekilsiz formda izlenmiştir. Ana materyal matriks mikrokristalen kalsit minerallerinden oluşmaktadır. Matris içerisinde ikincil mineral olarak çoğunlukla kuvars kristalleri öz şekilsiz formda gözlenmiştir (Şekil 7). Muhtemel kil mineralleri oluşumuna az oranda da olsa rastlanılmıştır. Opak mineral olarak veya damar dolgusu şeklinde demir minerali gözlenmemiştir. Kayaç boşluk oranı ve içerdiği mineral özelliklerine göre traverten özelliktedir.

\subsection{Darbe Dayanımı Deney Sonuçları}

Travertenlerden 40x40x40 mm boyutlarında 10 adet küp numune hazırlanmıştır. Darbe dayanımı deney düzeneğinde gerçekleştirilen darbe dayanımı deneyi sonucunda ortalama darbe dayanım değeri $6 \mathrm{Nmm} / \mathrm{mm}^{3}$ olarak belirlenmiştir.

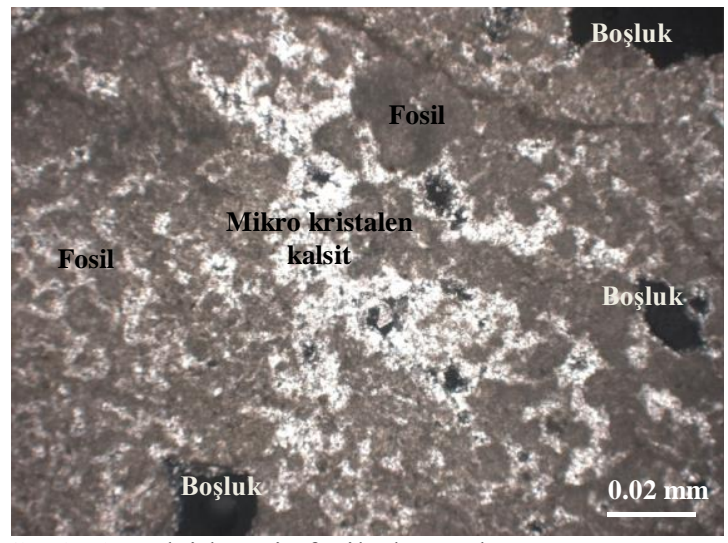

Şekil 6. Kalsitleşmiş fosil oluşumları

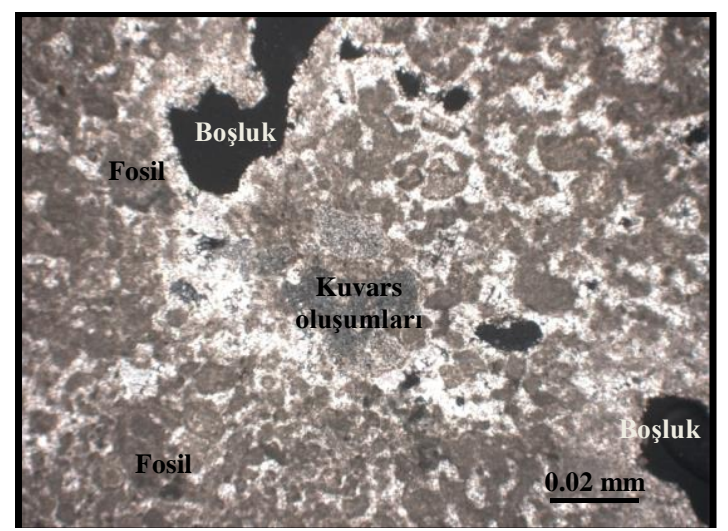

Şekil 7. Kayaç içerisindeki kuvars oluşumları

\subsection{Tek Eksenli Dayanımı Deney Sonuçları}

Deney numunelerinden standarda uygun boy/çap oranlarına sahip onar tane örnek hazırlanmıştır. TS 699 [4]'a uygun olarak hazırlanan örnekler hidrolik pres yardımı ile basınca maruz bırakılmış ve örnekler üzerinde gerçekleştirilen deney sonuçları Çizelge 2'de sunulmuştur.

\subsection{Eğilme Dayanımı Deney Sonuçları}

Numuneden 10 adet örnek hazırlanmış ve BS EN 12372 [8] standardına uygun olarak işleme tabi tutulmuştur. İşlem sonucunda Elazığ travertenlerinin eğilme dayanımları Çizelge 3'de verilmiştir. 
Çizelge 2. Traverten numunelerinin tek eksenli basınç dayanımı değerleri

\begin{tabular}{|c|c|}
\hline Örnek No & Basınç Dayanımı $(\mathrm{MPa})$ \\
\hline 1 & 52,6 \\
\hline 2 & 62,6 \\
\hline 3 & 57,6 \\
\hline 4 & 63,2 \\
\hline 5 & 59,6 \\
\hline 6 & 65,9 \\
\hline 7 & 67,5 \\
\hline 8 & 61,5 \\
\hline 9 & 62,7 \\
\hline 10 & 54,5 \\
\hline Ortalama & 60,76 \\
\hline Standart Sapma & 4,7 \\
\hline
\end{tabular}

Çizelge 3. Numunelerin eğilme dayanımı değerleri

\begin{tabular}{|c|c|}
\hline Örnek No & Eğilme Dayanımı (MPa) \\
\hline 1 & 6,03 \\
\hline 2 & 7,24 \\
\hline 3 & 6,64 \\
\hline 4 & 5,73 \\
\hline 5 & 6,33 \\
\hline 6 & 6,79 \\
\hline 7 & 5,70 \\
\hline 8 & 6,27 \\
\hline 9 & 5,91 \\
\hline 10 & 6,48 \\
\hline Ortalama & 6,31 \\
\hline Standart Sapma & 0,49 \\
\hline
\end{tabular}

\subsection{Atmosfer Basınci Altında Su Emme Deney Sonuçları}

Standarda uygun olarak hazırlanan 6 adet deney numunesi hazırlanmış ve deneye tabi tutulmuştur. Deney sonuçları Çizelge 4'de verilmiştir.

\subsection{Yangın Karşısındaki Davranışı}

Numuneler incelenerek yangın karşısındaki davranışı tayin edilmiştir ve numunelerin içeriğinde asfaltite ve organik içerikli bağlayıcıya rastlanmamıştır.
Çizelge 4. Numunelerin atmosfer basıncı altında su emme oranları (\%) değerleri

\begin{tabular}{|c|c|}
\hline Örnek No & $\begin{array}{c}\text { Atmosfer Basinc1 Altında } \\
\text { Su Emme Oranı (\%) }\end{array}$ \\
\hline 1 & 0,831 \\
\hline 2 & 0,898 \\
\hline 3 & 0,890 \\
\hline 4 & 0,863 \\
\hline 5 & 0,890 \\
\hline 6 & 0,997 \\
\hline Ortalama & 0,895 \\
\hline Standart Sapma & 0,056 \\
\hline
\end{tabular}

\subsection{Kılcal Etkiyle Su Emme Deney Sonuçları}

6 adet standarda uygun numune hazırlanmıştır ve deneye tabi tutulmuştur. Deney sonuçları Çizelge 5'de verilmiştir.

Çizelge 5. Traverten numunelerinin kılcal etkiye bağlı su emme katsayısı değerleri

\begin{tabular}{|c|c|}
\hline Örnek No & $\begin{array}{c}\text { Kilcal Etkiye Bağlı Su Emme } \\
\text { Katsayısı }\end{array}$ \\
\hline 1 & 2,760 \\
\hline 2 & 2,983 \\
\hline 3 & 2,076 \\
\hline 4 & 2,263 \\
\hline 5 & 2,669 \\
\hline 6 & 2,297 \\
\hline Ortalama & 2,578 \\
\hline Standart Sapma & 0,35 \\
\hline
\end{tabular}

\subsection{Açık Gözeneklilik ve Görünür Yoğunluk Deneyi Bulguları}

Altışar adet standarda uygun numune hazırlanmıştır ve deneye tabi tutulmuştur. Açık gözeneklilik deney sonuçları ve görünür yoğunluk deney sonuçları Çizelge 6'da verilmiştir. 
Çizelge 6. Numunelerin açık gözeneklilik ve görünür yoğunluk değerleri

\begin{tabular}{|c|c|c|}
\hline Örnek No & Açı Gözeneklilik (\%) & Görünür Yoğunluk $\left(\mathrm{kg} / \mathrm{m}^{3}\right)$ \\
\hline 1 & 2,240 & 2695 \\
\hline 2 & 2,320 & 2582 \\
\hline 3 & 2,400 & 2698 \\
\hline 4 & 2,320 & 2687 \\
\hline 5 & 2,400 & 2698 \\
\hline 6 & 2,080 & 2647 \\
\hline Ortalama & 2,293 & 2668 \\
\hline Standart Sapma & 0,12 & 1,73 \\
\hline
\end{tabular}

\subsection{Dona Dayanım Deneyi Sonuçları}

Standarda uygun olarak hazırlanan deney numuneleri dona maruz bırakılmadan önce eğilme dayanımı tayin edilmiştir. Daha sonra dona dayanım prosedürü uygulanmış ve don dayanımı sonunda numune tekrar eğilme dayanım deneyine tabi tutularak don sonrası dayanımdaki azalma don kaybı olarak kaydedilmiştir. Dona dayanım öncesi ve sonrası eğilme deneyine tabi tutulan numunenin deney sonuçları Çizelge 7'de verilmiştir.

Çizelge 7. Numunelerin don öncesi ve don sonrası eğilme dayanımı sonuçları

\begin{tabular}{|c|c|c|}
\hline Örnek No & $\begin{array}{c}\text { Don öncesi } \\
(\mathrm{MPa})\end{array}$ & $\begin{array}{l}\text { Don sonras1 } \\
(\mathrm{MPa})\end{array}$ \\
\hline 1 & 5,7 & 4,07 \\
\hline 2 & 6,3 & 4,22 \\
\hline 3 & 5,1 & 4,52 \\
\hline 4 & 5,7 & 4,28 \\
\hline 5 & 6,6 & 4,19 \\
\hline 6 & 6,3 & 4,37 \\
\hline 7 & 7,1 & 3,65 \\
\hline 8 & 7,6 & 3,98 \\
\hline 9 & 6,9 & 4,58 \\
\hline 10 & 6,0 & 4,21 \\
\hline Ortalama & 6,36 & 4.22 \\
\hline Std. Sapma & 0.74 & 0.27 \\
\hline \multicolumn{2}{|c|}{ Don sonrası kayıp (\%) } & 33,6 \\
\hline
\end{tabular}

\section{SONUÇLAR}

Elazığ bölgesi travertenlerinin kaplama taşı olarak kullanılabilirliğini belirlemek amacıyla, çalışma sahasından alınan örnekler, TS EN 1469 [3] standard 1 ve bu standartta belirtilen diğer standartlardaki birtakım deneylere tabii tutulmuş ve ilgili standarda göre sonuçlar değerlendirilerek yorumlanmıștır. Görünüș deneyi TS EN 1469 [3]'e göre araziden alınmış işlenmemiş numunenin perdahlanmış numunelerle görünüş bakımından benzeştiği gözlenmiştir. Yani deney numunelerinin renk, yapı ve gözeneklilik bakımından ana kayacı temsil ettiği sonucuna varılmıştır. Petrografik ve mineralojik incelemeler sonucunda kayacın porozitesinin yüksek mikro kristali dokulu sedimanter orijinli olduğu ve ayrışmaya neden olacak demir oluşumlarının oldukça az olduğu belirlenmiştir. TS 699 [4]'e göre tek eksenli basınç dayanım ve darbe dayanım değerlerinin uygun olduğu ve bu bakımdan kaplama taşı olarak kullanımında sakınca bulunmadığ 1 sonucuna varılmıştır. Yapılan deney çalışmaları, BS EN 13755 [7]'e göre numunelerin atmosferik basınç altında su emme katsayılarının \%0,1'den büyük olması nedeniyle özellikle sslak zeminlerde kullanılacak kaplama taşlarından beklenen özelliği taşımadığını göstermektedir. Yangın karşısındaki davranışı incelendiğinde, ilgili standartta TS EN 1469 [3]'e göre A1 (yangından etkilenmez) sınıfina girmesi nedeniyle yangına dayanıklı olduğu tespit edilmiştir. TS EN 1936'e göre kılcal etkiyle su emme ve açık gözeneklilik değerleri de yüksek olduğu gözlenmiştir. Görünür yoğunluk 
hesaplanan standart sapmaları beklendiği gibi düşük çıkmış, deney sonuçlarının güvenilirliği doğrulanmıştır. BS EN 12372 [8] standardına göre don sonrası eğilme dayanımının \%20'nin üstünde olduğu, malzemenin don sonrası eğilme dayanımlarının kaplama taşı olarak kullanılamayacağını ortaya koymuştur. Sonuç olarak, Elazı̆̆ travertenlerinin TS EN 1469 [3] standardında belirtilen kriterleri bazılarını sağlamadığı gözlenmiştir. $\mathrm{Bu}$ bağlamda; don oluşumu çok olan ve aşırı yağış alan bölgelerde dış ortamlarda kaplama taşı olarak kullanılmasının uygun olmadığı kanısına varılmıştır.

\section{TEŞEKKÜR}

Petrografik ve mineralojik analizlerde yardımlarını esirgemeyen Yrd. Doç. Dr. Nil YAPICI'ya teşekkürü bir borç biliriz.

\section{KAYNAKLAR}

1. Erdoğan, Y., 2011. Engineering Properties of Turkish Travertines, Scientific Research and Essay, 6(21), 4551-4566.

2. Bölücek, C., 2002. Derince (Keban-Elazığ) Çevresinde Dere Sedimenti Jeokimyasal Yönlendirme Çalışması, Hacettepe Üniversitesi Yerbilimleri Uygulama ve Araştırma Merkezi Bülteni, 25, 51-63, Ankara.

3. TS EN 1469, Nisan 2006. Doğal Taş Mamulleri-Kaplamada Kullanılan PlakalarÖzellikleri, Ankara.

4. TS 699, 2009. Doğal Yapı Taşları İnceleme ve Laboratuvar Deney Yöntemleri, TSE, Ankara.

5. TS EN 1936, Ocak 2010. Doğal Taşlar-Deney Yöntemleri-Gerçek Yoğunluk, Görünür Yoğunluk, Toplam ve Açık Gözeneklilik Tayini, Ankara.

6. TS EN 1925, Nisan 2000. Doğal Taşlar-Deney Metotları-Kılcal Etkiye Bağlı Su Emme Katsayısı Tayini, Ankara.

7. BS EN 13755, Nisan 2008. Natural Stone Test Methods-Determination of Water Absorption at Atmospheric Pressure.

8. BS EN 12372, Ekim 2006. Natural Stone Test Methods-Determination of Flexural Strenght Under Concentrated Load.
9. TS EN 12407, 2008. Doğal taşlar, Deney metotları, Petrografik inceleme, Ankara.

10. TS EN 12371, Ocak 2003. Doğal Taşlar, Deney Metotları-Dona Dayanım Tayini, Ankara.

11. TS EN 13501-1+A1, Nisan 2013. Yap1 Mamulleri ve Yap1 Elemanları, Yangın Sınıflandırması Bölüm 1: Yangın Karşısındaki Davranış Deneylerinden Elde Edilen Veriler Kullanılarak Sinıflandırma, TSE, Ankara. 
